\title{
Distal Mycotic Aneurysm of the AICA Mimicking Intracanalicular Acoustic Neuroma
}

\author{
Salvatore DiMaio, Gérard Mohr, Jean-Jacques Dufour, Steffan Albrecht
}

\begin{abstract}
Background: Among cases of cerebellopontine angle lesions, vascular lesions involving the internal auditory canal are extremely rare. We report a distal fusiform mycotic pseudoaneurysm of the anterior inferior cerebellar artery (AICA) that simulated an acoustic neuroma on presentation. Methods: A 60-year-old woman was investigated for recent onset of acute dizziness. Laboratory and radiographic investigations are presented, as well as the surgical management of the patient and pathological examination of the aneurysm. Conclusions: An exceptionally rare case of distal mycotic intracanalicular pseudoaneurysm of the AICA with intraluminal thrombus and fusiform anatomy is described. In our review of the literature (1966-present), only five other intracanalicular AICAaneurysms were encountered, none of which were infectious in etiology. The possible pathophysiologic mechanisms of distal AICA-aneurysms are discussed along with the currently available literature.
\end{abstract}

RÉSUMÉ: Anévrisme mycotique distal de l'ACIA simulant un neurinome acoustique intracanaliculaire. Introduction: Parmi les cas de lésions de l'angle ponto-cérébelleux, les lésions vasculaires impliquant le canal auditif interne (CAI) sont extrêmement rares. Nous rapportons un cas de pseudo-anévrisme mycotique fusiforme de l'artère cérébelleuse inférieure et antérieure (ACIA) dont le mode de présentation simulait un neurinome acoustique. Méthodes: Une femme âgée de 60 ans a été examinée pour un état vertigineux aigu d'apparition récente. Nous présentons les résultats des examens biochimiques et de radiologiques ainsi que le traitement chirurgical de la patiente et l'examen anatomopathologique de l'anévrisme. Conclusions: Nous décrivons un cas extrêmement rare de pseudo-anévrisme intracanaliculaire mycotique fusiforme de l'ACIA distale avec thrombus intraluminal. Selon notre revue de la littérature de 1966 à nos jours, seulement cinq autres anévrismes intracanaliculaires de l'ACIA ont été rapportés et aucun d'eux n'était d'étiologie infectieuse. Nous discutons des mécanismes physiopathologiques possibles des anévrismes de l'ACIA distale et de la littérature sur le sujet.

Can. J. Neurol. Sci. 2003; 30: 388-392

Among cases of cerebellopontine angle (CP) lesions, vascular lesions involving the internal auditory canal are extremely rare. We report a distal mycotic fusiform pseudoaneurysm of the anterior inferior cerebellar artery that simulated an acoustic neuroma on presentation. Its surgical management is described and possible pathophysiologic mechanisms are discussed along with the currently available literature.

\section{CASE RePort}

A 60-year-old woman in otherwise healthy condition experienced onset of acute dizziness in the context of a twenty year history of rightsided tinnitus that had recently accentuated. There was no history of chronic mastoiditis. She had no facial nerve disfunction or any hearing complaints, and audiological assessment was excellent (speech reception threshold (SRT) $10 \mathrm{~dB}$, speech discrimination score (SDS) 92\%). Magnetic resonance imaging (MRI) examination (Figure 1) revealed a $6-7 \mathrm{~mm}$ lesion in the proximal internal auditory canal occupying approximately $1 / 3$ of the porus and minimally protruding into the $\mathrm{CP}$ angle. The lesion was hyperintense in $\mathrm{T} 1$ and enhancing with gadolinium injection. On T2-weighted MRI, the lesion was found to be hypointense. On the basis of these findings a pre-operative diagnosis of right intracanalicular acoustic neuroma was made by both neuroradiologists and the neuro-otology team. In view of the excellent hearing, an attempt at hearing preservation was planned for removal of the mass.

\section{Operation}

The patient was placed in the left park-bench position with the appropriate needle electrodes placed for intraoperative monitoring of the

From the Divisions of Neurosurgery (SD,GM), Otolaryngology (J-JD) and Pathology (SA), Sir Mortimer B. Davis - Jewish General Hospital, McGill University, Montreal, QC, Canada

ReCEIVED JANUARy 22, 2003. ACCEPTED IN FINAL FORM APRIL 21, 2003. Reprint requests to: Gérard Mohr, Chief, Division of Neurosurgery, The Sir Mortimer B. Davis - Jewish General Hospital, 3755, Chemin de la Côte-Sainte-Catherine, Montreal, Quebec H3T 1E2 Canada. 
facial and vestibulocochlear nerves, as well as scalp electrodes for monitoring of auditory brainstem potentials. The patient had excellent early operative electrocochleogram recordings and satisfactory brain stem potentials. Straight retromastoid incision and circular suboccipital craniotomy was then performed to uncover a part of the transverse sinus and the sigmoid sinus. Exposure of the CP (Figure 2a) revealed a relatively voluminous vascular branch of the anterior inferior cerebellar artery (AICA) crossing posteriorly to the 7th and 8th nerves and in contact with a globular reddish lesion which appeared pulsatile to closer inspection. It became rapidly evident that this was not an acoustic neuroma but a very unusual case of intracanalicular fusiform aneurysm of the AICA. The aneurysm was quite adherent to the dura and there were significant amounts of clots within the lumen. Both facial and vestibulocochlear nerves were preserved but the cochlear potential and brainstem potential disappeared early on within the dissection and it was thought that in this unusual case the preservation of the hearing would not be possible. After removal of the posterior lip of the meatus, the aneurysmal sac was completely circumscribed and luxated out of the internal auditory canal and an attempt at clip reconstruction using even a fenestrated right angle clip precluded the preservation of the vessels and possible risk of fatal postoperative rupture. It was, therefore, decided in view of the fusiform nature of this aneurysm to proceed with a trapping excision using two clips proximal and two distal to the aneurysm (Figure 2b).

\section{Pathologic examination}

The specimen (Figure 3) consisted of a small artery that was greatly dilated and whose wall was extensively remodelled. Most of the lumen was occupied by recent thrombus with some peripheral, fibroblastic organization. The intima was thickened and consisted of loose fibroblastic tissue. The media was almost completely devoid of smooth muscle and was extensively replaced by organizing granulation tissue which formed much of the wall of the aneurysm. Scattered chronic inflammatory cells and hemosiderin deposits were present. The adventitia was thickened and fibrotic, and only a few microscopic remnants of internal elastic membrane were present. An infectious process was not identified in the examination using special stains.

Histological sections of the aneurysm were also analyzed by Dr. Tack
Ki Leung (pathologist, Montreal Heart Institute). He identified numerous scattered collections of bacteria within the mural thrombus and within the cytoplasm of surrounding phagocytic cells. These were identified as Gram negative coccobacilli, indicating the presence of a mycotic aneurysm. The specimen was further analyzed by the Armed Forces Institute of Pathology, Department of Defense, in Washington, DC, who described a pseudoaneurysm given that the wall was extensively formed by granulation tissue. In addition, evidence for an infectious process was not identified by special stains.

\section{Postoperative course}

Neurologic examination performed three hours after the surgery showed strictly no evidence of limb ataxia or nystagmus and facial nerve function was intact. Postoperative CT scan revealed no signs of cerebellar infarction. The patient's hearing was preserved and audiologic examination performed two weeks after the operation demonstrated maintained preservation of useful hearing (SRT $17 \mathrm{~dB}$, SDS 90\%) which was, however, slightly diminished. Infectious Diseases was consulted to identify potential sources of infection; however, exploration for an endocarditis and unusual Gram negative organisms, as well as additional investigations of this patient's intracranial vasculature and a systemic work-up for vasculidities were performed but turned out to be negative. In light of the lack of a clear source of infection or organism, antibiotic therapy was not initiated. The postoperative course was hence unremarkable; consequently no further investigations were undertaken and the patient was discharged home in good condition.

\section{Discussion}

Vascular lesions involving the internal auditory canal are rare. The reported incidence of AICA aneurysms is $0.1-0.5 \%,{ }^{1}$ and only five published cases of aneurysms occupying the internal auditory canal have been reported in the literature (Table). ${ }^{1-4}$ Fusiform aneurysms also represent rare entities; a number of large series have reported incidences ranging from $<0.2 \%$ to slightly under $1 \% .^{5}$ Among cases of CP lesions, the majority are vestibular schwannomas, whereas the remainder constitute a variety of rare tumours with limited imaging data. ${ }^{6}$ In our own

\section{Table: Summary of published cases of AICA aneurysms within the internal auditory canal}

\begin{tabular}{|c|c|c|c|c|c|c|}
\hline Author(s) & Age; Sex & Mode of onset & Signs and symptoms & CPA & Treatment & Outcome \\
\hline Hori et al ${ }^{10} 1971$ & $35 ; \mathrm{F}$ & Acute & $\begin{array}{l}\text { Headache, vomiting, facial palsy, } \\
\text { deafness, tinnitus, nystagmus, SAH }\end{array}$ & yes & Trapping & $\begin{array}{l}\text { Deafness, } \\
\text { tinnitus }\end{array}$ \\
\hline Kamano et al, ${ }^{1} 1986$ & $58 ; \mathrm{F}$ & Acute & $\begin{array}{l}\text { Headache, facial palsy, vertigo, } \\
\text { nuchal rigidity }\end{array}$ & no & Trapping & $\begin{array}{l}\text { Facial palsy, } \\
\text { deafness }\end{array}$ \\
\hline Inoue et $\mathrm{al}^{2} 1987$ & $43 ; \mathrm{F}$ & Acute & $\begin{array}{l}\text { Headache, nausea, vomiting, right } \\
\text { hearing disturbance, SAH }\end{array}$ & no & Clipping & $\begin{array}{l}\text { Facial palsy, } \\
\text { deafness }\end{array}$ \\
\hline Spallone et $\mathrm{al}^{4} 1995$ & $46 ; \mathrm{F}$ & Acute & Facial palsy, hearing loss, SAH & no & Trapping & $\begin{array}{l}\text { Facial paralysis, } \\
\text { hearing loss }\end{array}$ \\
\hline 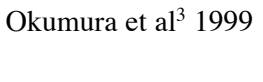 & $77 ; \mathrm{F}$ & Acute & $\begin{array}{l}\text { Headache, impaired hearing, tinnitus, } \\
\text { vertigo, nuchal rigidity, SAH }\end{array}$ & no & Trapping & No deficits \\
\hline Present study & $60 ; \mathrm{F}$ & Acute & Tinnitus, dizziness & yes & Trapping & No deficits \\
\hline
\end{tabular}

SAH : Sub-arachnoid hemorrhage; CPA : lesion mimicking CP angle tumour 
A
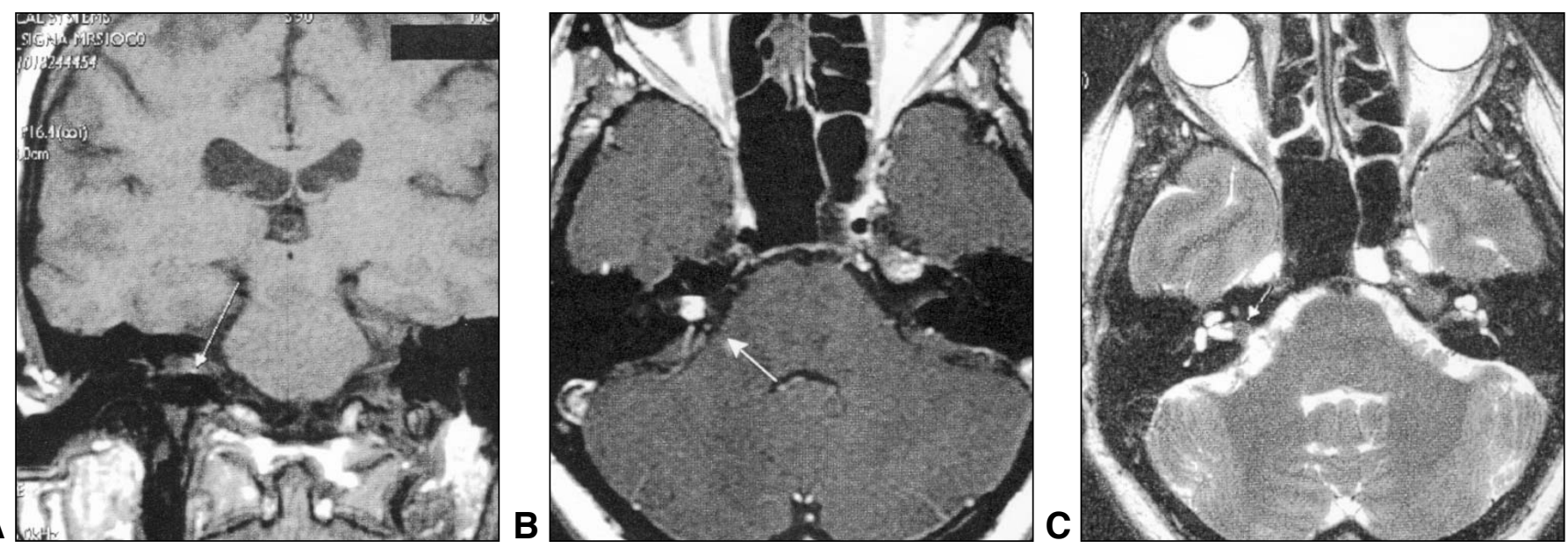

Figure 1: (a) Coronal Tl-weighted MRI image demonstrating right hyperintense intracanalicular mass (arrow) in a 60 year old lady investigated for acute-onset dizziness. (b) Axial Tl-weighted MRI with gadolinium infusion shows enhancement of the lesion (arrow). (c) In T2-weighted imaging the lesion was found to be hypointense (arrow) shown here in an axial section.
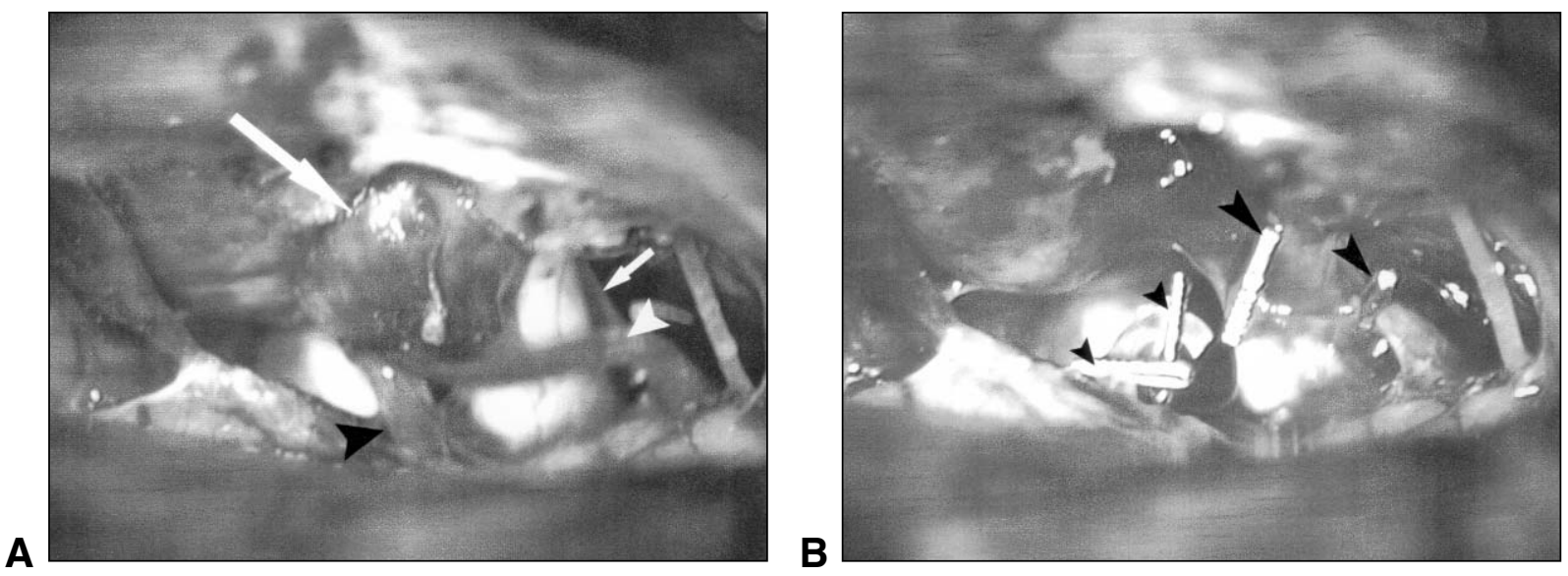

Figure 2: Exposure of the cerebellopontine angle (a) revealed an intracanalicular fusiform AICA-aneurysm (large arrow). The proximal (white arrowhead) and distal (black arrowhead) AICA loops are seen as well as the labyrinthine branch (small arrow). (b) Trapping excision of the aneurysm using two clips proximal (large arrowheads) and two distal (small arrowheads) to the lesion.

A
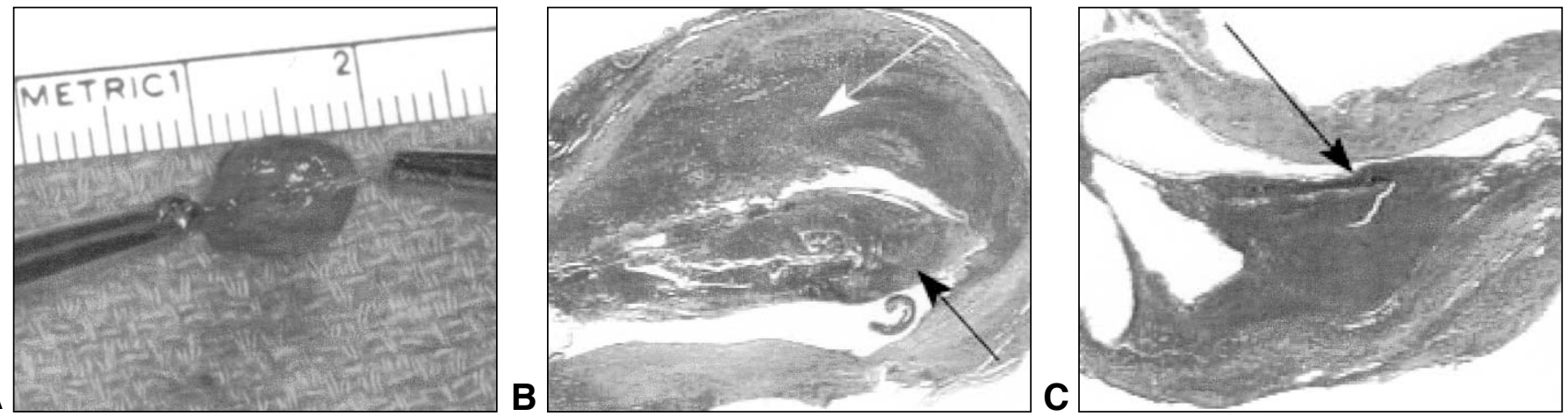

Figure 3: (a) Gross pathologic examination. The specimen consisted of a small artery that was greatly dilated, measunng 6-7 mm in its greatest diameter. $(b, c)$ Histopathologic sections of the aneurysm stained with hematoxylin and eosine demonstrate the presence of intra-lumenal thrombus (black arrows) and intimal thickening (white arrow). 
experience, from a series of 531 cases of $\mathrm{CP}$ angle lesions over a 21-year period (from Oct. 1981 to Feb. 2002) including 69\% of acoustic neuromas, ${ }^{7}$ only $3.4 \%$ of the cases involved vascular lesions, consisting of 14 PICA - vertebral artery aneurysms, three intracanalicular cavernous angiomas ${ }^{8}$ and one hemangioblastoma. ${ }^{9}$

From our Medline search of the literature (1966-present), five published cases of AICA aneurysms that were strictly intracanalicular were identified..$^{1-4,10}$ The clinical details of these reports including the present case are contained in the Table. Four of six cases presented with signs of sub-arachnoid hemorrhage and all cases had cranial nerve VII and VIII signs; a total of two cases also mimicked a $\mathrm{CP}$ angle tumour at presentation. None of the aneurysms were infectious in etiology. A trapping procedure to remove the aneurysm was performed in all but one case.

The tendency of intracanalicular vascular lesions to mimic acoustic neuromas is not uncommon. ${ }^{11}$ Two separate groups ${ }^{12-14}$ reported cases of non-intracanalicular AICA-aneurysms in which an initial diagnosis of $\mathrm{CP}$ angle tumour was made. In one case, ${ }^{13}$ a CT-scan-based pre-operative diagnosis of acoustic neuroma was made, and the AICA-aneurysm was discovered intraoperatively. In the latter case, ${ }^{15}$ a pre-operative CT was also done and a diagnosis of aneurysm was made during trans-otic exploration. In the present case, multiple intraluminal hemorrhages and thrombi appeared to have masked the "flowvoid" effect typical of aneurysms on MRI. Fibrin and clot retraction also both contribute to the shortening effect on T2. Hemosiderin, which was observed in the affected vessel wall upon pathologic examination, has a strong shortening effect on T2-weighted MRI given its high magnetic susceptibility. ${ }^{16}$ Furthermore, on the T1-weighted series, it is possible that methemoglobin present in the intra-luminal thrombi was responsible for the hyperintensity seen.

Fusiform aneurysms of nonatherosclerotic origin have been previously discussed in this journal. ${ }^{17}$ Histopathologic study of these aneurysms typically shows fragmentation of the internal elastic lamina, neoangiogenesis within the enlarged intima, intramural hemorrhaging with subsequent thrombus formation within the lumen, repetitive intramural hemorrhages from the newly formed vessels within thrombus and infiltration of the damaged vessel wall with acute and chronic inflammatory cells. ${ }^{18,19}$ Fusiform aneurysms have been shown to occur in the context of arterial dissection, ${ }^{18,20,21}$ as well as a number of autoimmune and connective tissue disorders, including systemic lupus erythematous, ${ }^{22}$ Marfan's syndrome ${ }^{23}$ and other related diseases. ${ }^{17}$ There have also been case reports of fusiform aneurysms developing in the peri-callosal vascular circulation following trauma, ${ }^{24-28}$ including two 10 -year-old children ${ }^{25}$ and a neonate. ${ }^{27}$

Mycotic aneurysms bear similar albeit nonspecific pathologic features to fusiform aneurysms, including signs of multiple hemorrhages, acute and chronic inflammatory cells, embolic phenomena and varying levels of vessel destruction. ${ }^{29}$ A large part of mycotic aneurysms arise from emboli from infected cardiac tissue as in subacute infective endocarditis. Other etiologies include contiguous sources of infection such as from skull osteomyelitis, cavernous sinus thrombophlebitis and meningitis. ${ }^{30}$ Bacterial organisms include staphylococcus aureus and enterobacteria as the most frequent, ${ }^{31}$ followed by enterococcus, pseudomonas and corynebacteria. Fungal intracranial aneurysms are more rare, and tend to occur particularly in diabetic and immunocompromised populations.

In pseudoaneurysms, or false aneurysms, the entire arterial wall is disrupted (unlike true aneurysms, in which there is preservation of the adventitia). Hemorrhage is therefore contained by surrounding tissue as well as blood clot. A mycotic pseudoaneurysm of the carotid bifurcation in the neck secondary to salmonella sepsis has been previously reported from our center, ${ }^{32}$ in which histopathological examination demonstrated clearly a defect in the wall of the junction between the common and internal carotid arteries, as well as abscess formation adjacent to the vascular lesion. It was hypothesized that the pathogenic mechanisms of formation of this pseudoaneurysm included primary endovascular infection, e.g., from an atheromatous plaque, and secondary development of an abscess, or primary abscess formation with secondary contiguous infection of the carotid bifurcation. It is possible that the present case represents a post-vasculitic aneurysm; ${ }^{33}$ alternatively, the patient might have sustained a transient bacteremia or septicemia that went unnoticed and led to the Infectious Diseases' investigations to turn up negative.

An exceptionally rare case of distal intracanalicular mycotic AICA-pseudoaneurysm with intraluminal thrombus and fusiform anatomy is described. Of our review of the literature only five previous intracanalicular aneurysms of the AICA have been identified, none of which were infectious in etiology. The pathologic features of fusiform and mycotic aneurysms have been described, along with their possible pathophysiologic mechanisms according to the currently available literature.

\section{ACKNOWLEDGEMENTS}

This case was presented at the Winter Meeting of the New England Neurosurgical Society, March 1, 2002, in Killington, Vermont. The authours thank Dr. Tack Ki Leung, pathologist, Montreal Heart Institute, and Dr. Allen P. Burke, pathologist, Armed Forces Institute of Pathology, for their collaboration on the pathological examination.

\section{REFERENCES}

1. Kamano S, Kirino $\mathrm{T}$, Mizuno S. Intrameatal aneurysm. Neurochirurgia 1986;29:28-30.

2. Inoue $\mathrm{Y}$, Morinaga $\mathrm{K}$, Matsumoto $\mathrm{Y}$, et al. A case of ruptured internal auditory meatus aneurysm. Surg Cerebr Str 1987;15:280284.

3. Okumura Y, Sakaki T, Hirabayashi H, et al. Intrameatal aneurysm successfully treated be meatal loop trapping--case report. Neurol Med Chir 1999;39:161-164.

4. Spallone A, De Santis S, Giuffre R. Peripheral aneurysms of the distal anterior inferior cerebellar artery. Case report and review of literature. Br J Neurosurg 1995;9:537-541.

5. Hayes WT, Bernhardt H, Young JM. Fusiform arteriosclerotic aneurysm of the basilar artery. Vasc Surg 1967;1:171-178.

6. Bohrer PS, Chole RA. Unusual lesions of the internal auditory canal. Am J Otol 1996;17:143-149.

7. Browning S, Mohr G, Dufour JJ, et al. Hearing preservation in acoustic neuroma surgery. J Otolaryngol 2001;30:307-315.

8. Dufour JJ, Michaud LA, Mohr G, et al. Intratemporal vascular malformations (angioma): particular clinical features. J Otolaryngol 1994;23:250-253.

9. Mohr G, Dufour JJ, Zeitouni A, Rappaport J, Browning S. Otoneurosurgical management of cerebellopontine angle lesions: the 
suboccipital approach revisited. In: Sanna M, Taibah A, Russo A, Mancini F (Eds). S.P.A. Acoustic Neurinoma and Other CPA Tumors. Rome: Monduzzi Editore 1999;6-12:303-314.

10. Hori T, Hirakawa K, Ishijima B, et al. Aneurysm in the internal auditory meatus. Case report. J Neurosurg 1971;35:605-609.

11. Maeta M, Saito R, Nameka H. False-positive magnetic resonance image in the diagnosis of small acoustic neuroma. J Laryngol Otol 2001;115:842-844.

12. Cantore GP, Ciapetta P, Vagnozzi R, et al. Giant aneurysm of the anterior inferior cerebellar artery simulating a cerebellopontine angle tumor. Surg Neurol 1982;18:76-78.

13. Dalley RW, Robertson WD, Nugent RA, et al. Computed tomography of anterior inferior cerebellar artery aneurysm mimicking an acoustic neuroma. J Comput Assist Tomogr 1986; 10:881-884.

14. Zager EL, Shaver EG, Hurst RW, et al. Distal anterior inferior cerebellar artery aneurysms: report of four cases. J Neurosurg 2002;97:692-696.

15. Gleeson MJ, Cox TC, Strong AJ. Aneurysm of the anterior inferior cerebellar artery mimicking an intracanalicular acoustic neuroma. J Laryngol Otol 1989;103:107-110.

16. Bradley WG. MR appearance of hemorrhage in the brain. Radiology 1993;189:15-26.

17. Findlay JM, Hao C, Emery D. Non-atherosclerotic fusiform cerebral aneurysms. Can J Neurol Sci 2002;29:41-48.

18. Nakatomi H, Segawa H, Kurata A, et al. Clinicopathological study of intracranial fusiform and dolichoectatic aneurysms. Insights on the mechanism of growth. Stroke 2000;31:896-900.

19. Vale F, Hadley MN. Pathology of intracranial aneurysms and vascular malformations. In: Batjer HH (Ed). Cerebrovascular Disease. Philadelphia: Lippincott-Raven, 1997:65-77.

20. Kato N, Ezura M, Takahashi A, et al. Intraaneurysmal embolization and parent artery trapping to treat a giant partial thrombosed vertebral artery aneurysm after surgical proximal clipping. Neurol Surg 2000;28:817-822.
21. Sagoh M, Hirose Y, Murakami H, et al. Late hemorrhage from persistent pseudoaneurysm in vertebral artery dissection presenting with ischemia: case report. Surg Neurol 1999;52:480483.

22. Orita T, Kajiwara K, Izumihara A. Ruptured aneurysm at the peripheral branch of the posterior cerebral artery with systemic lupus erythematous. No To Shinkei 1992;44:733-737.

23. Schievink WI, Parisi JE, Piepgras DG, et al. Intracranial aneurysms in Marfan's syndrome: an autopsy study. Neurosurgery 1997; 41:866-870.

24. Ide $\mathrm{Y}$, Wakuta $\mathrm{Y}$, Orita $\mathrm{T}$, et al. A case of iatrogenic traumatic intracranial aneurysm. Neurol Surg 1987;15:1353-1359.

25. Johnston SC, Halbach VV, Smith WS, et al. Rapid development of giant fusiform cerebral aneurysms in angiographically normal vessels. Neurology 1998;50:1163-1166.

26. Moriyama T, Shigemori M, Hirohata Y, et al. Multiple intracranial aneurysms following radiation therapy for pituitary adenoma; a case report. Neurol Surg 1992;20:487-492.

27. Tan MP, McConachie NS, Vloeberghs M. Ruptured fusiform cerebral aneurysm in a neonate. Childs Nerv Syst 1998;14:467469.

28. Wakabayashi Y, Nakano T, Isono M, et al. Dissecting aneurysm of the anterior cerebral artery requiring surgical treatment--case report. Neurol Med Chir 2000;40:624-627.

29. Barker DL, Prats AR. Mycotic aneurysms. Ann Surg 1954;139:84.

30. Clare CE, Barow DL. Infectious intracranial aneurysms. Neurosurg Clin N Am 1992;3:551-566.

31. Tunkel AR, Kaye D. The neurologic complications of infective endocarditis. Neurol Clin 1993;11:419.

32. Nader R, Mohr G, Sheiner NM, et al. Mycotic aneurysm of the carotid bifurcation in the neck: case report and review of the literature. Neurosurgery 2001;48:1152-1156.

33. Sinclair D, Mohr G. Cerebral vasculitis. In: Aminoff, M, Daroff, R. Encyclopedia of the Neurological Sciences. San Diego: Academic Press. b. Ref Type: 2003. In Press. 